\title{
Promoting Education Equity by Block Chain Technology
}

\author{
Qun Chen \\ School of Computer Technology \\ Zhuhai College of Jilin University \\ Zhuhai, China
}

\begin{abstract}
At present, violations and breach of educationrelated laws and regulations are frequent in China. The root cause is the management loopholes in school roll, including information discreteness, unsafe custody, difficult in verification, easy to manipulation and fraud. To a certain extent, these have been resulting in unfairness in education. Based on block chain technology, reconstructing the national integrated school roll management system can comprehensively solve those problems. With changing the existing educational management system, it will make school roll objective, integral, safe and available. And it will put an end to the chaos of education industry, promote educational equity and help return to the essence of education. Then education can truly guide the healthy development of individuals, families, society and the country.
\end{abstract}

\section{Keywords - block chain; education; equity; school roll}

\section{INTRODUCTION}

China is one of the countries that pay the most attention to education in the world, as well as one of the countries that do the best in educational equity. It is our basic state policy to rejuvenate the country through science and education. The Constitution states the fundamental right of every citizen to receive education. Since the founding of the People's Republic of China 70 years ago, by taking advantage of the superiority of the social system, we have made unified plans to build public schools, including primary and secondary schools and colleges covering all administrative districts. Small number of countries are specialized in the construction of normal colleges and universities, and as one of them, China has been continuously supplying a large number of teachers for schools at all levels every year.We have anexcellent system of education management, education guarantee, education incentive and education selection.We introduced nine-year compulsory education system decades ago.Since the enrollment expansion of colleges and universities in 1999, China has entered and gradually passed the stage of popularization of higher education. Now the enrollment rate of higher education has exceeded 50\%, and China has entered the stage of universalization of higher education. Nowadays, in order to achieve the great rejuvenation of the Chinese nation, it is proposed to take education and talents as the guide to build an innovative society.

However, in the context of reform and opening up and education marketization, there are loopholes in our education system. Incidents in breach of the education system rules still widely exist. For example, the use of power or special relationships or through bribes to obtain qualifications to enter good schools, immigrated examinees for the national college entrance examination, college impostor, establishment of bogus colleges, thesis fraud, false education background, manufacturing and selling fake diplomas, and so on. Corruption and irregularities in the educational system not only make people feel disgustful, but also cause the unfairness in education to some extent, which leads to the deviation between the social success model and the learning success model, makes the current education in China to be utilitarian and impetuous, causes the young people's perplexity and lack of desire to make progress, and seriously endangers the state and nation's development plan.

Education is not only related to the rise and fall of the nation and the future of the nation, but also the key to personal destiny. The measurement of an individual's educational experience and quality is based on his or her school roll. Unfortunately, the current conditions of scholl roll management in China are not satisfactory. At present, the school roll of Chinese students is managed by various schools and local educational administrative departments in a discrete way. Whether it is in the form of paper archives or electronic archives managed by computer, the administrator has the authority and convenient conditions to operate, and archives information are also easy to be damaged and lost due to improper storage or objective reasons, so it is not safe. In addition, the status data of each stage of learning form their own information island, which cannot be connected with each other in real-time, so it is difficult to verify in practice. In this way, on the one hand, the state cannot grasp the situation of educational resources, students and teaching performance in time, objectively, accurately and comprehensively, which will easily lead to the unfair distribution of educational resources and educational opportunities; On the other hand, it is difficult for the employer to grasp the quality of talents timely, comprehensively and accurately, which will easily lead to the unfair employment of talents. At the same time, it also makes it easy for ill-intentioned people to make improper profits through counterfeit. This is the root cause of the current educational chaos in China.

The emergence of block chain technology provides an effective technical support means to fillthe loopholes in the education system. This paper takes the construction of trustworthy school roll management system based on block chain as an example to explain why block chain technology can help promote education equity. Reconstructing of the national 
integrated school roll management system can solve the problems of objectivity, integrity, security, flexibility and usability of schoo roll without changing the existing educational management system, put an end to the chaos of education industry, promote educational equity and help return to the essence of education, so that education can truly guide the healthy development of individuals, families, society and the country.

\section{BlOCK CHAIN TECHNOLOGY}

Block chain was originally a distributed Internet technology developed for encrypting electronic money. It originated from Bitcoin, which was proposed in 2008. Over the Internet, by constructing a multi-node peer-peer network and applying technologies of encryption and decryption, HASH computing and consensus algorithm, the data (such as transfer informations between accounts, each of which is called a transaction) submitted by the network nodes are organized into blocks in a kind of data structure called Merkle-Tree. And then in the generated time sequence, links the blocks together as a chain with HASH pointers and forms a block chain.. The block chain maintains the same replica on each node of the peer-to-peer network and keeps them completely consistent through a consensus mechanism. The block chain is guaranteed by technical means so that the data stored on the block chain is permanently solidified and cannot be modified or deleted by anyone at any time. The data added to the block chain needs to be confirmed by consensus among multiple nodes in the peerpeer network according to a certain procedure, so it is unable to add additional data on any node without consensus. The block chain uses private-public key pair as the account, which can effectively hide the real identity of users. Block chain can also protect the security and privacy of user data through encryption and privilege control. Therefore, the block chain has the characteristics of decentralization, non-tampering, traceability, verifiability and privacy, which is not identified in any form of information technology in the past.

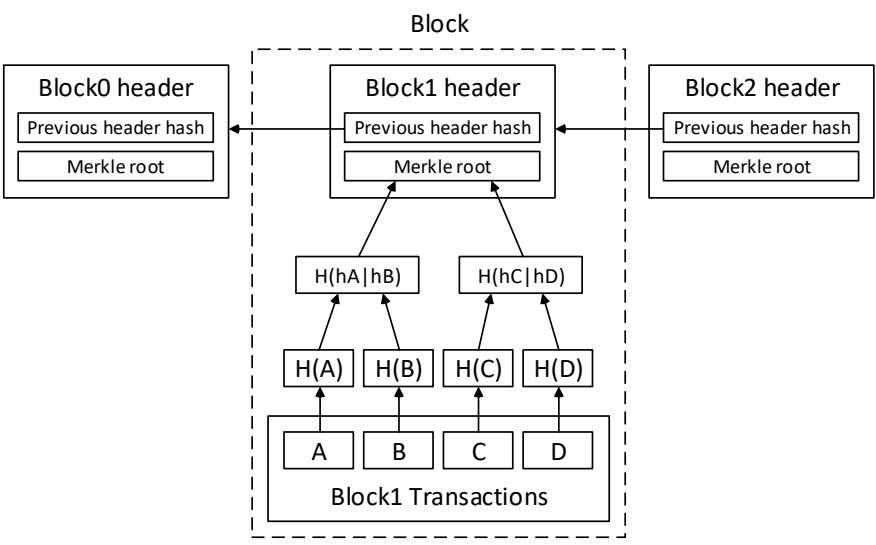

Fig. 1 Architecture of a block chain

The outstanding representative of the second generation block chain technology is Ethereum, which is mainly used in the application scenarios supported by virtual money. Ethereum introduced smart contract into its technology system. Smart contract is event-driven and can automatically execute programs about business logic, such as handling assets, based on preset conditions. The greatest advantage of smart contract is that it can use programmatic algorithms instead of human arbitration and execution of contracts. Once the smart contract is prepared and put into use on the block chain, it cannot be tampered and will run permanently, so as to ensure that the preagreed and regular transactions can be executed reliably on time and ensure the fairness of the society.

Because of the illegal activities such as money laundering caused by virtual currency and the reason of government regulation, the third-generation block chain developed in recent three or four years has abandoned the attribute of "currency" and strengthened the development of "chain" technology. The third-generation block chain technology is represented by Hyperledger Fabric, and it uses the underlying technical mechanism that supports the operation of virtual money, further strengthens the security management with user identity authentication and authorization management as the core, develops a more efficient and robust consensus algorithm, takes all means to increase the block-generatingspeed, and uses split-chaintechnology to enhance scalability and flexibility, so that block chain technology can be more widely used.

Block chain is a very impactful revolutionary Internet technology developed in the past decade. It can be used to build a self-running social trust network independent of third parties and promote the value interconnection of the whole society. Block chain technology is a brand-new decentralized infrastructure and distributed computing paradigm, which uses encrypted chain block structure to verify and store data, uses distributed node consensus algorithm to generate and update data, and uses smart contracts to program and operate data. At present, in industries likefinancial, telecommunications, medical andindustrial automation, block chain technology plays a very important role as the basic support platform. For example, for the BAAS platform based on block chain technology which serves for various scenarios of intelligent application of financial services, intelligent flaw detection scenarios of industrial automation, the entire life cycle of drug development, and food traceability etc., block chain technology has played its key role.

Block chain is a trust-building tool that brings improvements and enhancements in terms of data flow, maintenance and usage through a distributed IT architecture, and further brings value in business and social governance. At the technical level, the distributed IT architecture of block chain has the characteristics of decentralization, transparent and open, state consistency and strong dependence on cryptography. On the basis of these features, at the data level, the block chain can maintain data consistency on the basis of achieving multi-party consensus, prevent data from being tampered, and trace the whole process of data-based applications. At the business level, block chain can realize the smart contract of automatic execution, and can bring the value such as business process optimization, mode innovation and new business form cultivation in many fields. On this basis, it provides a new method for the wide participation, transparency and trustworthiness, opening and sharing, and auxiliary supervision of social governance. Block chain technology will be the cornerstone of the next generation Internet, i.e. value Internet. 


\section{BUILDING CREDIBLE SCHOOL RoLl MANAGEMENT SYSTEM BY BLOCK CHAIN}

At present, China's educational management system is divided into four levels, namely, national, provincial, prefectural and county levels. The national level is managed by the Ministry of Education, which is the highest administrative organization of education management. Each province is responsible for the administration of the educational administration departments of its subordinate cities and municipalities, as well as the colleges and universities within its jurisdiction; Each prefecture or city is responsible for the management of its subordinate district and county's education management departments, as well as high schools within its jurisdiction; Each district or county is responsible for the specific management of compulsory education schools and kindergartens within its jurisdiction. Colleges and universities are divided into two types- provincial type and ministerial type, which are respectively managed by the corresponding provincial or national ministries. National colleges and universities are directly managed by the Ministry of Education. Students can only take the college entrance exam in the province where they are registered. Depending on the location of their registered permanent residences, students may be enrolled in high schools in their respective prefectures orcities, junior high schools in their respective districts orcounties, and primary schools or public kindergartens in the vicinity of their registered place.

In the block chain system, the data already stored in the block chain cannot be modified or deleted, and can be traced back, so it is trustworthy. However, the school roll management system needs to be run continuously, new data are generated constantly, and the old data must be preserved permanently. According to this technical characteristic, and considering the status of the existing schoo roll management system in our country, the national school roll management system based on block chain can be designed into a hierarchical structure as shown in Figure 2.

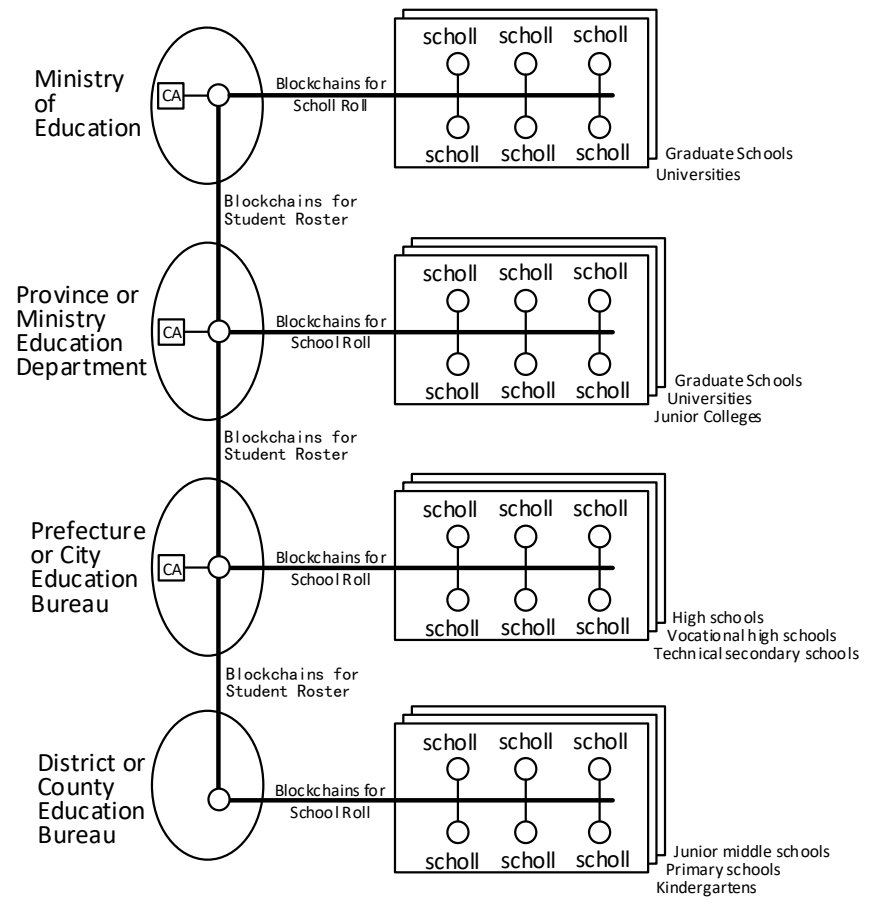

Fig. 2 Hierarchical architecture of school roll management system based on block chain.

Each district or county, prefecture or city, province and each national department/ministry (including the Ministry of Education) which manages the universities/colleges stablishes a block chain basedschool roll management subsystem. These four levels are interconnected according to the relationship between superiors and subordinates, thus forming an integrated national block chain based school roll management system.

At each managementlevel in each administrative region, the schools directly managed by it'seducation bureau (or department) are grouped according to their stages of learning. For example, there are kindergarten group, primary school group and junior high school group in adistrict orcounty, ordinary senior high school group, technical secondary school group and vocational high school group in aprefecture orcity, and college group, undergraduate group, master group, doctor group and postdoctoral group in aprovince orministry. In each group, the school roll data of the same termare organized on the same block chain, which is called the school roll chain. Each school and each educational administration department has a peer-to-peer network node, which carries each relevant school roll chain. School roll chain records the student's status record, such as academic performance, rewards and punishments, graduation thesis and so on. The school roll chain of the students who are still in studying is an active chain, and the school roll chain of the students who have graduated from this learning stage becomes an inactive chain. Inactive chains can be archived and saved offline to save storage space on peer-to-peer network node computers so that data on the working computer does not expand indefinitely over time. When you need to query the status data of previous students, you can load the archived inactive chain data back to the working computer. 
For ease of findingdata in massive school roll chains (including active chains and historical inactive chains), a separate kind of student rosterchain should be established beside the kind of school roll chain. The student roster chain is built in a block chain sub-system at the upper administrative level, where the education management department and its directly subordinate education bureaus (or department) are the peer-to-peer network nodes of the student roster chain. At the same time, these nodes carry the school rollchains of the schools directly under the corresponding education management departments.At these nodes, the student rosterdata for all students of the same termat the same learning stage are organized on the same student roster chain. In the student roster chain, the basic information of the students and the name of the corresponding school rollchain are registered. Cross-chain query betweenstudent roster chains and school roll chains can be realized on the peer-to-peer network nodes of education management departments.

There are three reasons for placing the student roster chain at a higher level than the school rollchain: First, it is technically convenient to carry out cross-chain query on the school roll chains; Secondly, it is administratively required that the school should submit the student's status information to the higher administrative department. Thirdly, the student roster chain data is simple, the amount of data is small, so it can store more student registration information in a centralized manner. At the school level, whenever a student changes his or her status, including naturalization and non-graduation withdrawal (e.g., repetition, skip or drop-out), the change should be reported to the immediatesuperior education management department in order to change the information in the corresponding student roster chain.

It shall establish CA Center and Consensus Center for block chain at prefecture-level, provincial level and Ministry of Education to serve the school roll chains and student roster chains running in their respective jurisdictions. The thirdgeneration block chain technology has advanced security privacy protection mechanism, consensus algorithm and splitchain mechanism. Through the control of smart contract, only authorized registered users can access the block chain system. Authorized access control and data confidentiality are realized under the combined effects of digital certificates, public-private key pairs, digital signatures, HASH and data encryption and decryption technologies. Authorized users at each level can only operate the data of current level. For example, the administrator of aschool can only access the school roll chain data of the school, and the administrator of aeducation management department can only access the student roster chain data and the school rollchain data in its jurisdiction. By means of Byzantine fault-tolerant or Kafka algorithm, the consensus among distributed nodes in the block chain can be realized, and the data of each computer node in the peer-to-peer network can be kept consistent and always correct. The splitchain mechanism enables the implementation of the above hierarchy. The construction of school roll management system based on block chain can ensure the objectiveness, truthfulness, real-time availability and permanent existence of the status information of all the students in the country.

\section{CREdible SchoOl Roll PROMOTES EdUCATIONAL EQUITY}

The school roll information stored in the block chain system cannot be tampered but can be traced and verified. While the system is connected across the whole country, it can be accessed seamlessly in real time, and can be supervised. This has a great deterrent and restriction effect on bureaucracy, corruption and illegal behavior in the field of education. Opportunists and outlaws will no longer be able to make use ofthe opacity, asymmetry, unreal-time, concealment and tampering of information to create time and space differences, thus exploiting "darkness under the light" for improper personal gain. After all, China is a legal society, traceable and blatant violation of the law and discipline is yetrelatively rare. In this way, the educational injustice caused by breach of laws and rules in the field of education can be greatly reduced or even completely eliminated, so as to promote educational equity and social equity.

(1) Make access to further education fair and equitable. With the block chain based scholl roll management system, the performance of the students and the results of the competitive examination are objective, true, open and transparent, and can be checked and compared in real time. If the supervision and audit system is perfected at the same time, it will be difficult to obtain the admission qualification by special care, because the supervision and audit means have become objective and easy.

(2) Social opportunities can be more and more fair. The school roll management system based on block chain can make the individual's performance in the school stage easy to check, and be comprehensive, objective and true, so when employing units select talents, the information they base on is more sufficient, and it is easier to select suitable talents.. Thenrelatively high-quality talents are more likely to get a good social opportunity, learning success and social success will be consistent, and the attitude of hard work and improvement for individual, family and society will be further encouraged.

(3) It shall put an end to the manufacture and sale of fake academic qualifications. A block chain based school roll management system makes it easy to verify the compliant and legal education background, and the query results are objective and true, soit is difficult for outlaws to sell fake diploma and fake qualification documents. The students and the public can no longer get profits through speculation, improperly obtain competitive advantages and opportunities, thus educational and social equity will be highlighted.

(4) Education management tends to be fair and just. The teaching quality of each school and the source and graduation direction of the students will be easily managed by the education management department in a timely, comprehensive and objective way through the school roll management system based on the block chain. The education management department will be more evidence-based and scientific when it allocates resources, formulate policies or carries out administrative intervention, so as to make education more fair and just in the whole country. 
(5) Teachers are more likely to be treated fairly and justly. Students' learning performance is a direct reflection of teachers' teaching performance. The objective status record of students in the block chain system can effectively avoid unfair treatment of teachers in assessment and promotion, and effectively stimulate teachers' enthusiasm for teaching, which in turn benefits students, so it is also a kind of educational equity for students.

\section{CONCLUSION}

Educational equity involves all aspects, among which the violation of laws and regulations in the field of education caused by the loopholes of school roll management is an important aspect of educational inequality in China. Reconstructing of the national-integrated school roll management system through the application of block chain technology will make relevant school roll information permanent solidified, non-tampered, traceable and real-time verified. This will fundamentally prevent such violations, thus enhancing the fairness of education. Of course, we should also further improve the education management and audit system, strengthen the construction of educational laws and regulations, and strictly enforce the law, so that the prevention and promotion effects of technical means can be truly brought into full play.

\section{ACKNOWLEDGMENT}

\section{Corresponding author: Qun CHEN}

Correspondence: 519041, School of Computing in Chu Hai College of Higher Education, Jilin University located in Sanzao Town, Jinwan District, Zhuhai City, Guangdong Province.

\section{REFERENCES}

[1] Huang Junfei and Liu Jie, "Review of Block Chain Technology," J. Journal of Beijing University of Posts and Telecommunications, February 2018, pp. 1-8.

[2] Shao Qifeng, Jin Chengqing, Zhang Zhao, Qian Weining and Zhou Aoying, "Block Chain Technology: Architecture and Progress," J. Chinese Journal of Computers., May 2018), pp. 969-988

[3] Shao Qifeng, Zhang Zhao, Zhu Yanchao and Zhou Aoying, "Overview of Enterprise Block Chain Technology," J. Journal of Software, April 2019 DOI:10.13328/j.cnki.jos.005775, http://kns.cnki.net/kcms/detail/11.2560.TP.20190409.1732.004.html

[4] Chen Weili and Zheng Zibin, "Block Chain Data Analysis: Current Situation, Trends and Challenges," J. Journal of Computer Research and Development, September 2018, pp. 1853-1870.

[5] Cai Weide, Yu Lian, Wang Rong, Liu Na and Deng Enyan, "Research on Development Method of Application System Based on Block Chain," J. Journal of Software, June 2017, pp. 1474-1487.

[6] Li Zhongzhen, Gao Chao, Liu Min, Dai Chengqin and Fan Yi, "Student Status Management System Based on Block Chain Technology," J. Journal of Sichuan University(Natural Science Edition), March 2019, pp 450-456.

[7] Tan Haibo, Zhou Tong, Zhao He, etc., "Archives Data Protection and Sharing Method Based on Block Chain," J. Journal of Software, April 2019, DOI:10.13328/j.cnki.jos.005770, http://www.cnki.com.cn/Article/CJFDTotal-RJXB20190409000.htm

[8] Muxuchong, "Maintaining the Fairness of College Entrance Examination Should not Neglect the Fairness of Education," J. People·Rule of Law, November2019, pp. 69.
[9] Gao Yuan, "Migrants for College Entrance Examination: Unfair Mobile Education," J. Consultative Forum, June 2019, pp. 44-46.

[10] Wang Aiyun, "Practice and Experience of the Communist Party of China in Promoting Education Equity in the Past 40 Years of Reform and Opening-up," J. Literature of Chinese Communist Party, June 2018 , pp. 70-79.

[11] Wang Shan, "On the Promoting Role of Lifelong Education System in Education Equity," J. Journal of Continuing Higher Education, June 2018, pp. 15-19.

[12] Ma Huanling and Jiang Chenhui, "Rent-seeking of Educational Power and Its Containment," J.Journal of Shenyang Normal University(Social Science Edition), January 2019, pp. 87-92.

[13] Kuang Hua, "Education Equity and State Responsibility Reconstruction under the Background of Marketization,” J. Citizen and Law, September 2014, pp. 11-15

[14] Gong Bizhen, "Strengthening the management of school roll archives is the fundamental guarantee to verify academic credentials," J. Office Operations, September 2014, pp. 175+182. 